REVISTA de

PEDAGOGIE

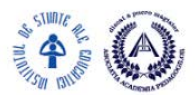

http://revped.ise.ro

Print ISSN 0034-8678; Online ISSN: 2559 - 639X

\title{
SCHOOL AS A LEARNING ORGANIZATION. SCHOOL CLIMATE IN DIGITAL SOCIETY
}

ŞCOALA CA ORGANIZAŢIE CARE ÎNVAŢĂ. CLIMATUL ŞCOLAR ÎN SOCIETATEA DIGITALIZATĂ

\section{Mariana Georgiana MORARU}

\author{
Journal of Pedagogy, 2019 (1), 41 - 55 \\ https://doi.org/10.26755/RevPed/2019.1/41
}

The online version of this article can be found at: http://revped.ise.ro/category/2019-en/

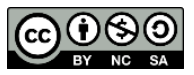

This work is licensed under the Creative Commons Attribution-NonCommercial-ShareAlike 4.0 International License

To view a copy of this license, visit http://creativecommons.org/licenses/by-nc-sa/4.0/ or send a letter to Creative Commons, PO Box 1866, Mountain View, CA 94042, USA.

Published by:

\section{INSTITUTUL DE ȘTIINȚE ALE EDUCAȚIEI}

http://www.ise.ro/

Further information about Revista de Pedagogie - Journal of Pedagogy can be found at:

Editorial Policy: http://revped.ise.ro/editorial-policy/

Author Guidelines: http://revped.ise.ro/the-writer-guide-2/ 


\title{
ŞCOALA CA ORGANIZA IE CARE ÎNVA Ă. CLIMATUL ŞCOLAR ÎN SOCIETATEA DIGITALIZATĂ
}

\author{
Mariana Georgiana Moraru* \\ Universitatea din Bucureşti \\ Bucureşti, România \\ marianamoraru01@gmail.com
}

\section{Rezumat}

Articolul propune spre analiză dimensiunile climatului educa ional din organiza ia şcolară, care nu doar facilitează procese de învă are, ci înva ă ea însăşi, dezvoltându-se în permanen ă. Importan a climatului educa ional în definirea unei şcoli este subliniată metaforic şi de către Freiberh şi Stein (1999), care descriau climatul şcolar ca fiind ,,inima şi sufletul şcolii şi esen a care îi determină pe profesori şi elevi să iubească şcoala şi să îşi dorească să fie parte din ea.” În ultimii ani au apărut studii îngrijorătoare cu privire la stările pe care, deopotrivă, elevii şi profesorii le asociază cu şcoala. Conform unui raport asupra stării educa iei din România publicat de UNICEF în 2013, ara noastră se află pe ultimul loc în Europa în ceea ce priveşte starea de bine a tinerilor. Nici când vine vorba despre profesori, realitatea educa ională nu stă foarte diferit. Un studiu realizat recent (2018) de Funda ia Romanian Business Leaders (RBL) şi D\&D Research arată că România ocupă antepenultimul loc în lume şi ultimul loc în Europa cu privire la indexul global al statutului profesorilor în societate. Pentru a putea construi un climat educa ional propice învă ării şi care să sus ină dezvoltarea şcolilor este mai întâi necesară o analiză atentă a numeroaselor dimensiuni ale climatului educa ional, în scopul în elegerii complexită ii şi valorii acestui concept.

Cuvinte-cheie: climat educa ional, dezvoltarea şcolii, dimensiuni, organiza ie şcolară, resurse educa ionale, societate informa ională.

* Drd. în Ştiin e ale Educa iei, Universitatea din Bucureşti, România. 


\begin{abstract}
The paper analyses the components of the educational climate in the school organization. The latter facilitates and co-participates in the learning processes while constantly developing itself. The importance of the educational climate in defining a school is metaphorically underlined by Freiberh and Stein (1999), which described the school climate as "the heart and soul of the school, and the essence that directs teachers and pupils to love school and to want to be part of it." In recent years, worrying studies have emerged about the feelings that both students and teachers associate with the school. According to a report on the state of education in Romania, published by UNICEF in 2013, our country is the last in Europe in terms of the well-being of young people. Even when it comes to teachers, the educational reality is not very different. A recent study (2018) by the Romanian Business Leaders Foundation (RBL) and D \& D Research shows that Romania occupies the ante-penultimate place in the world and the last place in Europe in global index of the status of teachers in society. In order to build a learning climate and to support the development of schools, it is first necessary to carefully analyze the many dimensions of the educational climate in order to understand the complexity and value of this concept.
\end{abstract}

Keywords: dimensions, educational climate, educational resources, information society, school development, school organization.

\title{
1. Organiza ia şcolară în contextul societă ii informa ionale - elemente definitorii
}

În contextul fenomenelor care caracterizează societatea contemporană, apar zilnic numeroase provocări în fa a cărora „,...şcoala trebuie să se adapteze, să ofere răspunsuri noilor cerin e impuse îndeosebi de pia a muncii. Şcoala a intrat (aproape for at) în era antreprenorială." (Păun, 2017, p. 119). Ne confruntăm cu un boom - informa ional, şcoala având nevoie de o reorganizare şi regândire a propriilor roluri şi obiective, care să vină în întâmpinarea nevoilor particulare ale fiecărui copil, dar şi ale fiecărui cadru didactic, în aşa fel încât să se asigure suportul necesar pentru a construi experien e educa ionale cu sens.

Şcoala este privită ca o organiza ie care se dezvoltă în permanen ă, această sintagmă fiind îndelung dezbătută şi studiată de numeroşi autori (Păun, 1999; Ion Barbu, 2009; Zaharia, 2013; Senge, 2016 etc.) care îmbogă esc literatura 
de specialitate cu defini ii şi explica ii cuprinzătoare.

O şcoală considerată organiza ie care înva ă ,presupune ca to i cei implica i în sistem să îşi exprime aspira iile, să-şi extindă domeniul cunoaşterii şi să-şi dezvolte abilită ile împreună" (Senge, 2016, p. 15). Expresia de organiza ie care înva $\breve{a}$ pune accentul pe dimensiunea umanistă, interac ională şi a valorificării experien elor şcolare, identificată şi de prof. Cătălina Ulrich (2016) în cartea sa „Învă area prin proiecte. Ghid pentru profesori”. Oamenii şi interac iunile dintre aceştia reprezintă sursa principală a dezvoltării şi învă ării.

Discursul public în educa ie aduce în prim-plan nevoia de formare a cadrelor didactice şi utilizarea mijloacelor moderne de învă ământ care să stimuleze interesul pentru învă are al copiilor numi i nativi digitali. SIVECO România (2014) afirma într-un articol că „,ne mişcăm repede într-o lume tot mai aglomerată în care se nasc rapid nebănuite oportunită i”. Care mai este, în acest context, rolul şcolii în formarea copiilor? Răspunsul este oferit de lumea ştiin ifică şi presupune, mai ales, educarea competen ei de adaptare a copiilor pentru care profesorii sunt principalii responsabili. În acest sens, avem nevoie de o calitate superioară a formării ini iale a profesorilor care să devină specialişti autonomi, liberi şi responsabili să decidă asupra elementelor definitorii ale procesului de învă ământ. Calitatea sistemului educa ional presupune, dincolo de curriculum şi legi, existen a unor profesori care să fie specialişti în educa ie, capabili să îşi asume decizii cu privire la metodele didactice utilizate, con inuturile predate, formele de organizare a copiilor etc.

Adaptabilitatea presupune capacitatea de a gestiona noul, schimbarea şi situa iile incerte sau anumite evenimente care apar (The Association of Independent Schools of New South Wales, 2016). Pentru a educa adaptabilitatea avem nevoie de profesori care să de ină această competen ă şi să manifeste deschidere şi flexibilitate. Suntem oare pregăti i să educăm în spiritul deschiderii pentru schimbare, al flexibilită ii şi al adaptabilită ii, dar să transmitem valori şi principii necesare unor interac iuni optime pe plan social? Acesta ar putea fi un subiect de investigare ştiin ifică foarte necesar şi captivant care ne-ar oferi o imagine coerentă asupra adaptabilită ii întregului sistem educa ional românesc. 
Într-un ghid publicat de OECD în 2016 se prezintă ideea conform căreia şcolile de astăzi trebuie să formeze elevii în spiritul unor cunoştin e şi competen e de care vor avea nevoie pentru a reuşi în situa ii necunoscute pentru viitorul în permanentă schimbare. Din păcate însă, multe şcoli arată astăzi aproape la fel cum arătau în urmă cu o genera ie şi prea mul i profesori nu manifestă interes pentru a descoperi şi aplica strategii didactice necesare nevoilor elevilor secolului 21. OECD (2016) propune un model integrat pentru în elegerea sintagmei de,,Şcoală ca organiza ie care înva ă”, acesta cuprinde şapte dimensiuni ce au în comun patru teme principale (the four Ts: trust, time, technology and thinking together): încredere, timp, tehnologie şi gândire colectivă. Figura nr. 1 prezintă modelul integrat pentru în elegerea şcolii ca organiza ie care înva ă, propus de OECD.

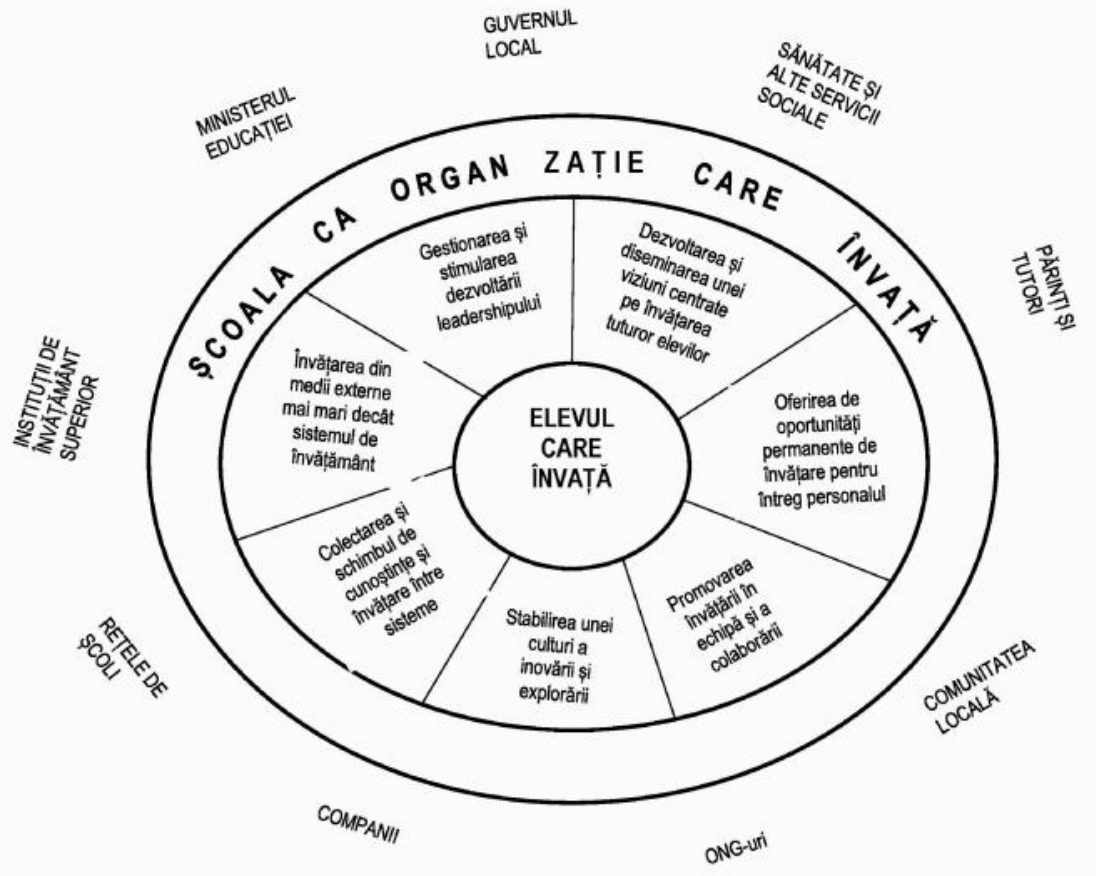

Figura nr. 1. Şcoala ca organiza ie care înva $\breve{a}$

Sursa: traducere şi adaptare OECD (2016) 
Modelul propus prezintă o imagine complexă a şcolii ca organiza ie în care rolul principal îl de ine elevul, acesta aflându-se într-un deplin proces de transformare.

\section{Climatul educa ional - dimensiuni cu impact asupra procesului educa ional}

Climatul educa ional este o realitate complexă a sistemelor de învă ământ a cărei în elegere şi analiză sunt necesare pentru proiectarea unor experien e educa ionale cu impact asupra educabililor.

Deseori apar în rândul practicienilor confuzii cu privire la definirea climatului educa ional, acesta fiind asociat întocmai doar cu anumite dimensiuni ale sale, cum ar fi rela iile din şcoli, siguran a, mediul şcolar sau cu termeni foarte apropia i ca în eles precum, cultură şcolară, atmosferă, starea şcolii. Acest capitol include o succintă analiză a principalelor defini ii ale climatului educa ional existente în literatura de specialitate precum şi a dimensiunilor principale ale acestuia.

\section{1. În elegerea conceptelor cheie - defini ii}

Climatul şcolar este considerat a fi un concept complex şi multidimensional (Maxwell, Reynolds, Lee, Subasic, Bromhead, 2017), care a fost definit de-a lungul timpului în diferite forme, cu accente distincte. Unii autori (Brookover et al., 1978; Haynes et al., 1997; Petrie, 2014 apud. Maxwell et al., 2017) consideră că no iunea de climat şcolar se referă la ,personalitatea nescrisă” a şcolii.

Pedagogul Emil Păun (1999) descrie climatul organiza ional ca fiind ,ambian a intelectuală şi morală care domneşte într-un grup, ansamblul percep iilor colective şi al stărilor emo ionale existente în cadrul organiza iei..." (Păun, 1999).

Al i autori (Cohen et al., 2009, p. 182, apud. Maxwell et al., 2017) sunt de părere că prin climat şcolar se în elege calitatea şi caracterul vie ii şcolii. 
Un concept apropiat ca sens de climatul şcolar este acela de cultură şcolară, cercetătorii în domeniu identificând asemănări şi deosebiri şi încercând să ofere defini ii cât mai coerente şi exacte pentru cei doi termeni. Gruenert (2008) oferă o diferen iere clară între cultura şcolară şi climatul şcolar, opinia lui fiind că felul în care facem lucrurile defineşte cultura şcolii, iar felul în care ne sim im se referă la climatul şcolar (Crown, apud Guenert, 2008).

O altă delimitare a celor două elemente componente ale şcolii este propusă de către Emil Păun (1999) care subliniază dominan a obiectivă a culturii care se poate transpune în comportamentul oamenilor, în timp ce climatul constituie dimensiunea subiectivă a şcolii (Păun, 1999).

Climatul educa ional este influen at de mai multe variabile printre care D. K. Allen (2003) identifică o serie de şase factori care au legătură cu percep iile angaja ilor asupra managementului schimbării: frecven a, predictibilitatea, deschiderea, gradul de participare, caracterul discontinuu sau continuu al naturii schimbării şi stilul persuasiv sau coercitiv de luare a deciziilor. Acelaşi cercetător descoperă faptul că este mai probabil ca abordările axate pe management să contribuie la dezvoltarea unui mediu insecurizant caracterizat prin demotivarea personalului, precau ie, dorin ă scăzută de asumare a riscurilor sau discre ie şi şanse ridicate să apară rezisten a la schimbare. La polul opus, în mediile unde rela iile sunt bazate pe colegialitate, s-a observat dezvoltarea unui grup mai puternic, caracterizat printr-o mai mare dorin ă de a manifesta deschidere şi de a împărtăşi informa ii, prin existen a mai multor conflicte cognitive şi rela ii interpersonale pozitive (Allen, 2003).

2.2. Dimensiuni ale climatului educa ional - analiză în contextul secolului XXI

În ciuda faptului că este dificil să se stabilească o defini ie general acceptată pentru climatul şcolar, majoritatea cercetătorilor sunt de acord cu opinia conform căreia conceptul de climat şcolar este unul multidimensional care include dimensiuni fizice, sociale şi academice. 
Dimensiunea fizică se referă la elemente precum aspectul şcolii, numărul de elevi şi profesori din şcoală, organizarea claselor, resursele disponibile, siguran ă şi confort. Aspecte ce au legătură cu rela iile dintre elevi, profesori şi restul personalului, comportamentele profesorilor fa ă de elevi sau cu implicarea elevilor şi a profesorilor în procesele de luare a deciziilor, sunt definitorii pentru dimensiunea socială. Dimensiunea academică a climatului şcolar se referă la calitatea instruirii, aşteptările profesorilor cu privire la performan ele elevilor, monitorizarea rezultatelor elevilor şi comunicarea către părin i a acestora (Loukas, 2007).

Thapa et al. (2013) investighează climatul educa ional din şcoli din perspectiva a cinci dimensiuni definitorii: siguran a, rela iile, predarea şi învă area, mediul institu ional, procesul de dezvoltare a şcolii.

Chiar dacă nu există o opinie comună cu privire la elementele definitorii pentru climatul educa ional, oamenii de ştiin ă din cadrul Centrului Na ional pentru Climat Şcolar (NSCC) au încercat o sintetizare a cercetărilor despre climatul şcolar şi au propus cinci mari arii din perspectiva cărora poate fi în eles climatul şcolar (mediul extern, siguran a, predarea şi învă area, rela iile, personalul angajat). Acestea sunt asemănătoare cu dimensiunile identificate de Thapa et al. (2013), fiecare dintre ele implicând, la rândul lor, mai multe sub-dimensiuni din care rezultă în total 12 dimensiuni ale climatului şcolii (Kane, Hoff et al., 2016).

În tabelul de pe pagina următoare se pot analiza cele 12 dimensiuni ale climatului şcolii şi indicatorii majori aferen i fiecăreia dintre ele. Această propunere de analiză a dimensiunilor climatului şcolar este complexă şi include elemente prevăzute de majoritatea cercetătorilor în domeniul climatului educa ional. 
Tabelul nr. 1. Dimensiunile climatului şcolii şi indicatori majori

Dimensiuni Indicatori majori

Siguran a

1. Reguli şi norme

2. Sentimentul siguran ei fizice

3. Sentimentul siguran ei socio-emo ionale

Predarea şi învă area

4. Sus inerea pentru învă area

5. Învă area socială şi civică
Comunicarea clară a regulilor cu privire la violen a fizică, la abuzul verbal, hăr uire şi tachinare; o aplicare clară şi coerentă a normelor demonstrată prin interven ia adul ilor.

Elevii şi adul ii se simt proteja i de abuzurile fizice.

Elevii şi adul ii se simt proteja i de abuzul verbal, tachinare sau excludere.

Utilizarea unor practici de predare suportive precum: încurajări şi feedback constructiv, oportunită i variate pentru demonstrarea cunoştin elor şi competen elor, sus inere pentru asumarea de riscuri şi gândire independentă, atmosferă bazată pe dialog şi întrebări, provocări academice, abordarea diferen iată.

Asigurarea suportului pentru dezvoltarea cunoştin elor, a competen elor şi dispozi iilor sociale şi civice, precum: ascultare activă, rezolvare de conflicte, auto-reflectare şi reglare emo ională, empatie, responsabilitate personală şi luare de decizii bazate pe etică.

Rela iile interpersonale

6. Respectul pentru diversitate

7. Suport social - pentru adul i

8. Suport social - pentru elevi

Respectul mutual pentru diferen ele individuale (de gen, rasă, cultură etc.) la toate nivelurile: şcoală-elev-elev; adult-elev; adult-adult şi în general, respectarea tuturor normelor pentru toleran ă.

Crearea unui pattern de rela ii bazate pe sprijin şi aten ie a profesorilor pentru elevi, incluzând aşteptările ridicate pentru succesul elevilor, dorin a de a-i asculta pe elevi şi de a-i cunoaşte ca personalită i şi preocuparea personală pentru problemele elevilor.

Crearea unui pattern de rela ii interpersonale bazate pe suport între elevi incluzând: prietenie în socializare, în rezolvarea problemelor, pentru ajutor din punct de vedere academic şi pentru integrarea elevilor noi.

\section{Mediul institu ional}

9. Conectarea şcolii / Angajamentul

10. Materialele fizice înconjurătoare

Identificarea pozitivă cu şcoala şi normele sale pentru participarea completă în via a şcolii, a elevilor, a personalului angajat şi a familiilor.

Cură enie, ordine şi apelarea la facilită i, resurse şi materiale adecvate pentru mediul şcolar.

\section{Personalul angajat}

\section{Leadership}

12. Rela ii profesionale
Administra ie care creează şi comunică o viziune clară şi care este accesibilă pentru personalul şcolii şi sus ine dezvoltarea acestuia.

Rela ii şi atitudini pozitive în rândul personalului şcolii care sus in lucrul efectiv împreună. 
Al i autori prezintă analize ale climatului şcolar din perspectiva unor elemente similare celor surprinse de Kane, Hoff et al., punând accentul asupra rela iilor şi procesului educa ional. Cohen, McCabe et al. (2009), spre exemplu, prezintă cinci elemente care intră în alcătuirea climatului şcolar:

1. Rela iile (respectul pentru diversitate, colaborare, comunicarea cu părin ii etc.).

2. Predarea şi învă area (calitatea predării, valorizarea creativită ii, dezvoltarea socială, emo ională şi etică, dezvoltarea profesională, leadership etc.).

3. Siguran a (fizică şi emo ională, manifestate prin diferite elemente specifice mediului fizic sau comportamentelor din şcoală).

4. Mediul fizic (spa iu adecvat).

5. Sentimentul apartenen ei (sentimentul de regăsire în comunitatea şcolară, angajament, entuziasmul elevilor, dar şi al profesorilor).

Dacă am încerca să includem într-o singură clasificare dimensiunile climatului educa ional, identificate de specialiştii în domeniul educa iei, am ob ine o imagine globală şi detaliată asupra factorilor care influen ează eficien a proceselor educa ionale din perspectiva climatului educa ional. Prezentăm în tabelul nr. 2 o propunere de clasificare a dimensiunilor climatului educa ional, care doreşte să fie accesibilă celor care doresc să studieze conceptul în cauză. Propunerea se bazează pe analiza clasificărilor dimensiunilor climatului educa ional care există în literatura de specialitate, o parte dintre ele fiind prezentate într-o formă adaptată şi în cadrul articolului.

Tabelul nr. 2. Dimensiuni generale ale climatului educa ional Dimensiuni

Subdimensiuni

\begin{tabular}{|c|c|}
\hline \multirow{3}{*}{ MEDIUL FIZIC } & Resursele materiale disponibile \\
\hline & Organizarea spa iilor de învă are \\
\hline & Siguran a în spa iul şcolii \\
\hline \multirow[t]{2}{*}{ MEDIUL PSIHOSOCIAL } & $\begin{array}{l}\text { Rela iile din cadrul şcolii } \\
\text { - } \quad \text { elevi - elevi } \\
\text { - } \quad \text { elevi / părin i / personal nondidactic } \\
\text { auxiliar - profesori } \\
\text { - } \quad \text { profesori / elevi / părin i / personal } \\
\quad \text { nondidactic auxiliar - manager şcolar }\end{array}$ \\
\hline & Sentimentul apartenen ei \\
\hline \multirow{3}{*}{ DEZVOLTAREA ORGANIZA IONALĂ } & Rezultatele elevilor \\
\hline & Formarea personalului didactic şi nondidactic \\
\hline & Dotarea cu materiale noi \\
\hline
\end{tabular}


Modelul propus încearcă să surprindă într-o manieră personală ideile prezentate în literatura de specialitate de către cercetătorii care au teoretizat subiectul climatului educa ional. Activitatea de predare-învă are este inclusă în rela iile care se stabilesc între profesori şi elevi, în primul rând, clasificarea propunând 3 dimensiuni majore (mediul fizic, mediul psihosocial şi dezvoltarea organiza ională) care înglobează subdimensiuni ce au legătură între ele. Dezvoltarea organiza ională apare ca o dimensiune majoră deoarece, în contextul actual caracterizat prin instabilitate şi schimbare rapidă, aceasta reprezintă un element care ar trebui să fie în aten ia permanentă a şcolilor.

Ideile dimensiunilor „Mediul fizic” şi „Mediul psihosocial” se regăsesc şi la Loukas (2007), Cohen, McCabe et al (2009) Kane, Ho et al. (2016) şi au o relevan ă deosebită în contextul caracteristicilor copiilor epocii digitale care au nevoie de mijloace variate de facilitare a învă ării. Dezvoltarea organiza ională, a treia dimensiune propusă, este o viziune care se regăseşte în studiile lui Kane, Hoff et al. (2016) precum şi în modelele propuse de National School Climate Center din SUA şi care poate fi privită ca un rezultat al elementelor componente ale primelor două dimensiuni.

Cele trei dimensiuni propuse cuprind câteva elemente cheie necesare a fi luate în considerare pentru asigurarea unor servicii educa ionale de calitate în contextul caracteristicilor societă ii actuale. Aşa cum se prezintă şi în studiul ISE „Cultura elevilor şi învă area” (Cuciureanu et al. 2014), provocările ridicate de elevii de astăzi necesită abordări de ordin psihologic şi pedagogic, în aşa fel încât profesorii să se apropie de elevi, să îi în eleagă pentru a reuşi să identifice mijloacele adecvate de motivare a copiilor. Integrarea cu succes a noilor tehnologii în activită ile didactice implică o pregătire atentă a cadrelor didactice, idee care, deşi există de multă vreme în discursurile publice, nu se transferă eficient şi în practică. Astfel, riscăm să dezvoltăm o şcoală în care se întâlnesc două lumi distincte care pot uşor să intre în contradic ie, lumea profesorilor şi a elevilor. Cum apropiem cele două realită i? Teoretic de inem o multitudine de solu ii, în practică rămâne încă o întrebare deschisă în mintea profesorilor şi a cercetătorilor în domeniul educa iei. 


\section{Rela ia dintre noile tehnologii şi dezvoltarea climatului educa ional}

Societatea secolului XXI este caracterizată printr-un ritm deosebit de alert al dezvoltării noilor tehnologii care se actualizează şi se transformă în fiecare zi. Copiii au acces la gadget-uri, internet şi aplica ii care le stimulează interesul pentru a descoperi lucruri noi şi care fac parte din vie ile fiecăruia dintre ei. În acest context putem discuta despre digitalizarea şcolii la nivelul fiecăreia dintre dimensiunile climatului său şcolar.

Un sus inător al schimbării stilului în care trăim este şi scriitorul Alvin Toffler care afirma că „oamenii şi societă ile au nevoie să înve e modalită i prin care să se adapteze şi să gestioneze schimbările rapide prin transformarea inova iilor tehnologice în ceva ce poate fi controlat colectiv", făcând astfel legătura dintre schimbare şi tehnologie (Toffler, 1981, apud Wan Fariza Wan Zakaria, 2012, p. 7).

Ultimele studii despre modul în care elevii digitali preferă să utilizeze tehnologiile şi cum este influen ată învă area acestora dacă se folosesc tehnologii moderne au arătat că utilizarea echipamentelor moderne conduce la creşterea calită ii învă ării şi a interac iunilor din rândul elevilor (Raja et. Nagasubramani, 2018). Se pare că transferul informa iilor în memoria copiilor se produce mai uşor dacă predarea este înso ită de mijloace moderne, care sunt mai aproape de lumea reală a elevilor. Mediul fizic al şcolii, prima dintre dimensiunile climatului şcolar pe care am propus-o în capitolul anterior, are nevoie de o gamă variată de mijloace audio-vizuale care să îi apropie pe copii de şcoală şi să le men ină şi stimuleze curiozitatea pentru a sus ine procesul de învă are.

Utilizarea noilor tehnologii în procesele de predare-învă are din clasele de elevi este un îndemn prezent în majoritatea discursurilor publice pe tema educa iei, utilizarea tehnologiilor poate conduce la rezultate pozitive şi în calitatea climatului educa ional. Apropierea copiilor de activită ile şcolare poate fi facilitată de introducerea unor mijloace moderne de învă are care sunt accesibile şi care oricum fac parte din vie ile copiilor.

Lumea contemporană se împarte în două categorii de persoane în func ie de felul în care interac ionează şi utilizează noile tehnologii: nativii digitali şi 
imigran ii digitali. Nativii digitali sunt copiii care s-au născut în epoca digitală şi care au avut acces la tehnologii moderne încă de la cele mai fragede vârste. Marc Prensky (2001), cercetătorul care introduce în literatura de specialitate termenii de nativi digitali şi imigran $i$ digitali, afirmă că nativii digitali sunt copiii născu i după anul 1980, an valabil pentru constatările sale din Statele Unite ale Americii.

În România nu poate fi luat ca referin ă acelaşi an ca în SUA pentru această categorisire, deoarece contextul na ional a condus la o dezvoltare mai lentă a ării noastre din perspectiva noilor tehnologii. Literatura de profil din România îi numeşte drept nativi digitali pe cei născu i după anul 1987 sau chiar după 1994, în anumite studii.

Dacă anii naşterii nativilor digitali nu sunt foarte bine delimita i la noi în ară, sunt destul de clare criteriile pe care nativii digitali le îndeplinesc, mai exact aceştia sunt copii care au crescut într-o lume în care au fost înconjura i de computere, jocuri video, telefoane şi alte gadget-uri (Prensky, 2001). Din acest motiv, Prensky (2001) afirmă că aceşti copii au competen e de utilizare a noilor tehnologii datorită accesului neîngrădit şi timpuriu la utilizarea unor astfel de resurse.

Pe de altă parte, eticheta de ,imigran i digitali” este oferită persoanelor care nu au avut acces la tehnologii moderne din primii ani de via ă, ci au învă at mai târziu să le utilizeze şi să le transforme în parteneri în munca lor cotidiană şi nu numai, ci şi să le integreze în vie ile lor.

Au apărut însă dezbateri pornind de la teoria lansată de Prensky, dezbateri care prezintă idei conform cărora nativii digitali nu ar de ine neapărat competen ele necesare pentru utilizarea corectă a noilor tehnologii (ECDL România, 2015). Profesorii, majoritatea imigran i digitali, ar putea să preia responsabilitatea educării elevilor în spiritul utilizării conştiente şi corecte a noilor tehnologii.

Un alt aspect care se află în centrul interesului cercetătorilor în domeniul impactului noilor tehnologii asupra sistemului educa ional este legat de modul în care înva ă copiii şi tinerii numi i ,digital natives”. Comunitatea cercetătorilor este de acord cu ideea conform căreia structurile cognitive ale nativilor digitali sunt diferite de cele ale imigran ilor digitali. Aceasta 
este o concluzie pe care practicienii au nevoie să o analizeze în activită ile lor, în aşa fel încât să în eleagă particularită ile dezvoltării elevilor şi să proiecteze experien e de învă are cu sens.

$\mathrm{Cu}$ privire la diferen ele dintre nativii digitali şi imigran ii digitali, în „Teaching the digital generation”, Frank Kelly, Ted McCain şi Ian Jukes (2009) exprimă puncte de vedere similare cu cele ale lui Prensky despre felul în care noile tehnologii au influen at comportamentele, gândirea şi felul în care nativii digitali înva ă. Există numeroase studii cu privire la stiluri de învă are diferite ale copiilor, la inteligen e multiple pe care este imperios necesar să le avem în vedere în calitate de specialişti în educa ie, în aşa fel încât să avem succes în activită ile educa ionale proiectate.

Dezvoltarea organiza iilor şcolare, o dimensiune majoră a climatului şcolar, presupune şi aten ia, în activitatea de proiectare a experien elor educa ionale, la elementele prezente în microsistemele sociale şi familiale din care apar in copiii. Pentru a crea un climat propice dezvoltării, care să îi motiveze pe copii să devină parte activă în propriile procese de învă are, climatul educa ional în care se desfăşoară procesul de învă ământ este necesar să includă elemente din realitatea copiilor. Utilizarea cu modera ie şi aten ie a gadget-urilor în activită ile de la clasă poate reprezenta un ingredient care să facă diferen a în eficien a proceselor educa ionale.

\section{Concluzii}

În contextul societă ii secolului XXI, în care ritmul dezvoltării tehnologiilor este foarte rapid, climatul educa ional are nevoie să ofere o mai mare aten ie mijloacelor de învă ământ moderne, care fac parte din vie ile tuturor celor implica i în procesul de învă ământ, mai ales ale copiilor.

Climatul educa ional reprezintă un termen complex care înglobează factorii cheie ce pot asigura eficien a procesului educa ional, precum activitatea profesorilor, spa iul fizic al şcolii, sentimentele asociate cu şcoala de către profesori şi elevi, în primul rând. O mai mare grijă pentru dezvoltarea elementelor componente ale climatului educa ional ar putea conduce la îmbunătă iri semnificative în dezvoltarea sistemului nostru educa ional. 
Utilizarea noilor tehnologii în procesele instructiv-educative din şcoală reprezintă un îndemn pentru practicienii din sistemul de învă ământ, care ar putea ob ine rezultate pozitive cu copiii atât în planul performan ei şcolare, cât şi la nivelul atitudinii şi motiva iei pentru învă are a copiilor.

Ştim deja că rolul central al profesorului nu mai este cel de transmitere de informa ii, ci de designer de experien e de învă are relevante pentru copii, ceea ce presupune valorificarea poten ialului elevilor, implicarea acestora în procesele decizionale de la clasă şi atenta îndrumare în fiecare etapă a procesului de învă are.

\section{Referin e}

- Crown, A. (2012). The importance of building a safe and caring school climate.Wellbeing@School research. Disponibil la: http://www.minedu.govt.nz/ NZEducation/EducationPolicies/Schools/Policy AndStrategy/Planning ReportingRelevantLegislationNEGSAndNAGS/TheNationalAdministration GuidelinesNAGs.aspx. (accesat la: 04.08.2018)

- ECDL România. (2015). Eşecul nativilor digitali. Europa se confruntă cu o genera ie pierdută. Disponibil la: https://ecdl.ro. (accesat la: 20.02.2019)

- Cuciureanu, M., Alecu, G., Badea, D., Catană, L., Mircea A. Ş., Tarău, I., \& ăranu, A. (2014). Cultura elevilor şi învă area. Disponibil la: https://www.ise.ro/ wp-content/uploads/2015/08/Cultura-elevilor-si-invatarea.pdf. (accesat la: 20.06.2019)

- Ion Barbu, D. (2009). Climatul educa ional şi managementul şcolii. Bucureşti: Editura Didactică şi Pedagogică.

- Kivunja, C. (2014). Theoretical Perspectives of How Digital Natives Learn. International Journal of Sustainability in Higher Education, 3(1), 94-109. https://doi.org/10.5430/ijhe.v3n1p94.

- Loukas, A. (2007). What Is School Climate. Leadership Compass Journal, $5(1)$.

- Maxwell, S., Reynolds, K., J., Lee, E., Subasic, E., \& Bromhead, D. (2017). The impact of school climate and school indentification on academic achievement: Multilevel modeling with student and teacher data. Frontiers in Psychology. Disponibil la: www.frontiersin.org. (accesat la 15.08.2018)

- Păun, E. (1999). Şcoala, o abordare sociopedagogică. Iaşi: Editura Polirom.

- Păun, E. (2017). Pedagogie. Provocări şi dileme privind şcoala şi profesia didactică. Iaşi: Editura Polirom. 
- Prensky, M. (2001). Digital natives, digital immigrants. Disponibil la: https:// www.marcprensky.com. (accesat la: 20.02.2019)

- Raja, R., \& Nagasubramani, P. C. (2018). Impact of modern technology in education. Journal of Applied and Advanced Research, 3. doi:10.21839/jaar.2018.v3S1.165.

- Research Romania Team. (2018). Studiu: Statutul profesorilor din România este cel mai scăzut din Europa. Disponibil la: https://www.researchromania.ro/ 2018/03/studiu-statusul-profesorilor-din-romania-este-cel-mai-scazut-dineuropa/. (accesat la 11.08.2018)

- Senge, P. (2016). Şcoli care înva ă. A cincea disciplină în educa ie. Bucureşti: Editura Trei.

- SIVECO România. (2014). Cum ne pregătim copiii pentru meseriile de mâine? Disponibil la: http://www.siveco.ro/. (accesat la: 28.02.2019)

- The Association of Independent Schools of New South Wales. (2016). The link. Where researchers meets practice. Disponibil la: https://www.aisnsw.edu.au/ DesignerFiles/Articles/7f276ad4-b47a-4b98-bd98-6805cff44eed.pdf. (accesat la 27.02.2019)

- Ulrich, C. (2016). Învă area prin proiecte. Ghid pentru profesori. Iaşi: Editura Polirom.

- U.S. Department of Education, Office of Safe and Healthy Students. (2016). Quick guide on making school climate improvements. Disponibil la: http:// safesupportivelearning.ed.gov/SCIRP/Quick-Guide. (accesat la 14.08.2018)

- Wan Fariza Wan Zakaria, A. (2012). Alvin Toffler: Knowledge, Technology and Change in Future Society. Disponibil la: https://www.researchgate.net/. (accesat la 24.02.2019)

- European and national level. Investments in human capital development in education and training are needed to strengthen the system's ability to respond to rapid changes in society and the labor market.

The online version of this article can be found at: http://revped.ise.ro/category/2019-en/

\section{(CC) BY-NC-SA}

This work is licensed under the Creative Commons Attribution-NonCommercial-ShareAlike 4.0 International License.

To view a copy of this license, visit http://creativecommons.org/licenses/by-nc-sa/4.0/ or send a letter to Creative Commons, PO Box 1866, Mountain View, CA 94042, USA.
Versiunea online a acestui articol poate fi găsită la: http://revped.ise.ro/category/2019-ro/

\section{(cc) BY-NC-SA}

Această lucrare este licen iată sub Creative Commons Attribution-NonCommercial-ShareAlike 4.0 International License.

Pentru a vedea o copie a acestei licen e, vizita $i$ http://creativecommons.org/licenses/by-nc-sa/4.0/ sau trimite i o scrisoare către Creative Commons, PO Box 1866, Mountain View, CA 94042, SUA. 